\title{
SEVEN YEARS IN THE FIELD OF HEALTH IMPACT ASSESSMENT: TAKING STOCK AND FUTURE DIRECTIONS
}

\author{
Rebecca Morley, MSPP; Ruth Lindberg, MPH, MUP; Bethany Rogerson, MSSP; Emily Bever; Keshia M. Pollack, PhD, MPH
}

\section{Abstract:}

The U.S. spends more per person on medical care than any other country, yet we have worse health indicators than many comparable wealthy nations. Research increasingly shows that social, economic, and environmental factors determine our health; however, there is still an emphasis on curing illnesses rather than addressing these underlying causes of disease. The Health Impact Project is a collaboration of the Robert Wood Johnson Foundation and The Pew Charitable Trusts, established in 2009 to promote and support the use of health impact assessment (HIA). As of January 2016, there were 386 HIAs either completed or in progress in the US in a variety of sectors - up from 62 HIAs in 2009. Although built environment HIAs still make up the largest sector of practice, other topics are emerging including education, criminal justice, and labor and employment. As the field matures, we are presented with new opportunities and challenges. In this article we offer lessons learned from our experience over the last seven years, and a view into the future of HIA. Specifically, we discuss the challenges and promises of making health a routine consideration in decision-making, translating HIA recommendations into policy, monitoring and evaluating the impact and outcomes associated with HIAs, promoting health considerations in federal decisions, and using HIAs as a tool for promoting health equity.

\section{Background}

An ever-growing body of research shows that the policies shaping our social, economic, and built environments have a significant impact on Americans' health. Research has demonstrated how factors such as the affordability and quality of housing, concentrated neighborhood poverty, transportation-related pollutants, and access to employment, education, and affordable, healthy foods affect health (National Research Council, 2011). Despite this, most money dedicated to improving health in the US is spent on medical care (Institute of Medicine, 2014). To improve population health outcomes and health equity, data and pragmatic recommendations for protecting and promoting health need to be factored into the public policy process.

HIAs have emerged as a widely used tool for promoting the inclusion of health considerations into public policy.
HIAs offer an opportunity for a more robust and democratic policymaking process, strengthening relationships among stakeholder groups and giving community members a stronger voice in decisions that affect them (Bourcier, Charbonneau, Cahill, \& Dannenberg, 2015).

The Health Impact Project-a collaboration of the Robert Wood Johnson Foundation and The Pew Charitable Trusts-was established in 2009 as a national initiative to promote and support the field of HIA as a way to integrate health considerations into decision-making outside the health sector. Our initial goals were to: (1) coordinate and promote efforts to increase the use of HIAs; (2) support up to 15 HIA demonstration projects at the state, local, and tribal levels; (3) develop and manage a training and technical assistance network; (4) complete HIAs of two federal policies that affect health; and (5) conduct and disseminate
$\Psi$
RICHARD M. FAIRBANKS SCHOOL OF PUBLIC HEALTH
INDIANA UNIVERSITY 
a comprehensive review of laws and regulations to identify opportunities to use HIAs to influence decisions.

Over seven years, we have attracted and invested more than $\$ 22$ million in growing the field of practice, including funding over 100 assessments, conducting four federal-level HIAs, supporting training for more than 1,300 individuals, and serving as a convener for the field. The HIA field has grown tremendously. As of January 2016, in the US, there were 386 HIAs either completed or in progress in 41 states, at the federal level, in the District of Columbia, and in Puerto Rico-up from 62 HIAs in 2009. Over half of the HIAs conducted to date have been on local decisions (54\%), while about $18 \%$ have focused on state level decisions. The remaining HIAs are split among the federal, regional, and county levels. The types of organizations leading or collaborating on HIAs are diverse. Of the HIAs reported on our online map, government agencies have conducted nearly half $(49 \%)$, with the remaining conducted by non-governmental organizations $(25 \%)$, academic institutions (22\%), and other organization types (4\%) (Health Impact Project, n.d.-b). About $70 \%$ of the HIAs conducted to date have been applied to decisions in the built environment (37\%), transportation $(19 \%)$, and natural resources $(11 \%)$. HIAs have also been applied to decisions in other sectors, such as housing, agriculture, climate change, criminal justice, and economic policy (Health Impact Project, n.d.-b).

As the field of HIA expands and matures, we are presented with new opportunities and challenges. This paper describes our perspectives on the state of the field, current challenges, and future opportunities in five distinct areas: (1) making health a routine consideration in decision-making; (2) translating HIA recommendations into policy; (3) monitoring and evaluating the impact and outcomes associated with HIAs; (4) promoting health considerations in federal decisions; and (5) using HIA to promote health equity.

\section{Making Health a Routine Consideration in Decision- Making}

Despite increased interest in public health among professionals in sectors such as planning, housing, and community development, the integration of these considerations into decision-making is not standard practice. HIA practitioners are exploring a range of approaches to embed health into decision-making processes and common practices of various sectors.

One strategy is to build on existing legal authorities or to create new ones that facilitate the incorporation of health in decision-making or the use of HIA and related approaches. For example:

- The legal support for HIAs is already in place through policies such as the National Environmental Policy Act (NEPA) and similar laws at the state level. These existing authorities have been previously described at length (Health Impact Project and Arizona State University, 2012).
- State policymakers are increasingly exploring how HIAs can help identify the potential and often overlooked health consequences of policies, plans, programs, and projects across a range of sectors. The National Conference of State Legislatures (NCSL) conducted a review of state legislation and statutes identifying and addressing HIAs and found that between 2009 and May 2014, 17 states considered 56 bills that would create a mandate for some consideration of health effects when making decisions (National Conference of State Legislatures, 2014). Many of the analyses proposed in these bills would not fit the strict definition of an HIA, but eight states have considered legislation that incorporated most elements of a formal HIA. One example of state HIA legislation is what is commonly known as the Healthy Transportation Compact. Enacted by the Massachusetts Legislature in 2009, the Compact establishes the use of HIAs to determine the health effects of state transportation projects (An Act Modernizing the Transportation Systems of the Commonwealth, 2009; Massachusetts Department of Transportation, n.d.).

Another strategy for making HIA routine practice is to develop organizational infrastructure, institutional support, leadership, and process changes. This approach includes adding HIA responsibilities to job descriptions, developing and formalizing partnerships within and across agencies, and identifying sustainable sources of funding. In 2012, the Health Impact Project expanded its funding opportunities to provide grants for this purpose. For example, between 2013 and 2016:

- The Tri-County Health Department in Denver, Colorado included "Health in All Policies" in their strategic plan as a way to better connect the built environment and public health sectors. Tri-County's Board of Health approved a budget for a new position to make progress toward this goal through the Department's Land Use and Built Environment Program.

- Oregon Health Authority collaborated with the Oregon Department of Transportation to develop a tool that models how specific transportation policy and funding decisions would relate to changes in physical activity.

- The Los Angeles Department of Public Health established the Health Impact Evaluation Center to develop the capacity and systems to routinely conduct HIAs. As part of their efforts, this center is creating screening tools and protocols to guide the agency's decisions on when to conduct rapid HIAs, as well as materials to facilitate completion of the screening and scoping steps.

A third strategy is to build health into the way other sectors do business by streamlining the HIA steps or through a 
"checklist" approach. For example:

- In the built environment and housing sectors, the Health Impact Project partnered with the U.S. Green Building Council (USGBC) and Enterprise Community Partners to embed health information into the Leadership in Energy and Environmental Design (LEED) certification system and the Enterprise Green Communities Criteria, respectively. These updated green building standards define a process by which architects, designers, and developers can consider the connections between the design, construction, and operation of buildings and public health. The Green Communities Criteria, first launched in 2004, is the leading green building standard for affordable housing in the U.S. and has been adopted by 23 states and eight major cities. In these locations, competitive funding streams critical to affordable housing development, such as states' Qualified Allocation Plans for allocating Low Income Housing Tax Credits and municipal affordable housing finance products, list certification to the Criteria either as a requirement or a preferential condition of funding. As of February 2016, over 500 affordable housing buildings containing approximately 29,000 units have received the certification, with over 50,000 more units on the path to certification. The 2015 version of the Criteria requires that developers identify potential resident health factors and design their projects to address resident health and wellbeing. An optional criterion calls for the developer, at the pre-design phase of development and continuing throughout the project life cycle, to collaborate with public health professionals and community stakeholders to assess, identify, implement, and monitor achievable actions to enhance health-promoting features of the project and minimize features that could present risks to health (Enterprise Green Communities, 2015). Approximately 250 projects are expected to implement the required health criterion by June 2016. A similar credit is being piloted by USGBC as part of its LEED system, an international green building certification program. Between the system's inception in 2000 and 2015, USGBC certified more than 26,600 real estate projects and more than 70,000 residential units worldwide across all sectors of the building industry, including affordable housing, commercial real estate, schools, homes, and neighborhoods.

- In the transportation sector, as part of its 2035 regional transportation plan, the Nashville Area Metropolitan Planning Organization (MPO) in Tennessee adopted new health scoring criteria for selecting and funding transportation projects, dedicating 60 of the 100 points to health promoting projects. Seventy percent of the selected roadway projects included active transportation elements, compared with roughly two percent in the prior plan. As part of its 2040 plan, the
MPO now dedicates 80 of 100 points to health promoting projects (Nashville Area Metropolitan Planning Organization, n.d.).

- In the planning sector, Meridian Township, Michigan, adopted a checklist-based tool that allows new proposed development projects to be evaluated according to health criteria that include access to safe places to exercise and healthy foods, design that facilitates social interaction, and standards for air and water quality (Charter Township of Meridian, n.d.). Planners work with each developer based on the findings of the evaluation to incorporate design elements that will improve health. In the 10 years since implementation, this simple approach has resulted in dozens of healthsupportive modifications.

Institutions such as banks, hospitals, and foundations have the ability to impact health equity through their lending, land acquisition and development, and investments, respectively. We are exploring policy and financial levers that can facilitate widespread use of HIA and related approaches. For example, the Patient Protection and Affordable Care Act [ 9007, 26 U.S.C. 501(c) (2010)] requires non-profit hospitals to conduct community health needs assessments and create community health improvement plans. In addition, building on prior state legislative efforts, the Health Impact Project is testing a "health note" to integrate potential health considerations into legislative analysis. A health note is similar to a fiscal note, and provides a brief, objective, nonpartisan summary of the potential positive and negative health impacts of a proposed bill. The health note draws upon the principles of HIA, but is streamlined for use on a large number of legislative proposals within a short timeframe.

As the field of HIA has matured, it is possible that for some decisions we have enough information about the potential health effects and corresponding mitigation strategies to move directly into implementation. The field could benefit from a central repository of sector- and decision-specific information and tools that could facilitate the translation of past HIAs into policy, and make HIA practice more accessible to professionals in a range of sectors outside of health. For example, the Health Impact Project has supported the National Center for Healthy Housing and the National Housing Conference to develop guidance for incorporating health into housing decisions. Similar efforts are underway to facilitate HIA practice in other sectors, including planning and disaster recovery.

Translating HIA Recommendations into Policy There remains a need for targeted HIAs that inform specific decision points, and focus on translating HIA recommendations into policy. One time HIAs targeting specific decisions can bring new evidence and stakeholder involvement into a decision that has the potential for substantial impact on health or health equity.

The policy impacts of past HIAs are numerous. For 
example, an HIA on the design of a modern streetcar in Tempe, Arizona was used by the Tempe Citizen Advisory Committee to inform the final streetcar system design. Based on the HIA recommendations, the City of Tempe established a weekly farmers' market to improve access to healthy food, as well as other goods and services. Similarly, as a result of an HIA on a community transportation plan in Decatur, Georgia, the city implemented a comprehensive set of infrastructure improvements to enhance the accessibility, safety, and connectivity of sidewalks, intersections, and streets for users of all ages and abilities. An HIA in Connecticut contributed to a new law that calls for the identification of state funds to remediate hazardous housing conditions and centralization of this funding within a single agency.

In an evaluation of $23 \mathrm{HIAs}$, the recommendations in 11 of the HIAs could be directly linked to the way decisions were developed or implemented, 11 of the HIAs changed the decision-making process, and 14 influenced changes beyond the decision under consideration (Bourcier, Charbonneau, Cahill, \& Dannenberg, 2015). However, the same evaluation found that maintaining the HIA's influence after the report's release is an often overlooked or missing step. HIA teams in 10 of the 23 cases did not adequately disseminate the recommendations or follow up on implementation, and only one HIA established a detailed monitoring plan to track the implementation of the HIA recommendations (Bourcier, Charbonneau, Cahill, \& Dannenberg, 2014). Often, grants end shortly after release of the HIA report, leaving little time to implement the report recommendations. Further, the funding timeframe does not allow grantees to capture the impact of HIAs on policy changes.

Health Impact Project grantees must include a monitoring and evaluation plan, and our grant selection criteria prioritize proposals with strong plans and partnerships to support ongoing engagement with the policies that will follow after the HIA. Despite these requirements and selection criteria, it is possible that longer grant periods or funding for implementation and monitoring could go a long way toward increasing the impact of HIAs. In addition, with a modest infusion of additional resources, many of our prior grantees and their partners are poised to translate HIA recommendations into policy.

One important consideration in moving HIA recommendations into policy is the role of advocacy in HIA. Some practitioners have expressed concerns that using HIA as a tool for advocacy could conflict with the HIA value of "ethical use of evidence" since the advocacy viewpoint could mean the group conducting the HIA has a preconceived policy outcome. The risk, therefore, is that decisionmakers will become skeptical about the objectivity of the tool, thereby diminishing its future value. When screening, organizations should reference the practice standards to decide whether an HIA is the most appropriate approach, if the goal is to support a specific advocacy objective. Organizations may ultimately choose not to use HIA if bringing diverse perspectives, and often opposing viewpoints, to present a balanced document is contrary to their overarching advocacy strategy. One approach that has proved successful is for organizations with established positions on a topic or issue to collaborate with a third-party. The third-party is responsible for conducting an independent and objective assessment, and the advocate can use the results of the HIA as part of a broader advocacy campaign. For HIAs led by advocacy organizations, the key is to ensure that a neutral party could read the report and come to his or her own conclusion - in other words, that the assessment is based on the best available evidence regarding potential health impacts, and presents the facts fairly and fully.

In the future, we will explore opportunities to support implementation of recommendations identified through HIAs. We also hope to identify ways that HIA practice and advocacy can be mutually supportive. For example, HIAs can generate objective data that advocacy organizations can use in their campaigns. Likewise, advocacy organizations know the priorities of the communities they serve and can help HIA practitioners select topics of importance to them. We also will help document and scale the strategies that are most likely to lead to the adoption of HIA recommendations in decisions, building on lessons from prior evaluations and input from the field.

\section{Monitoring and Evaluating the Impact and Outcomes Associated with HIAs}

Evaluations of HIAs in the US have documented their direct effects on decisions in non-health sectors as well as indirect effects, such as building consensus and relationships among decision-makers and their constituents, increased awareness of health among stakeholders, and giving community members a stronger voice in decisions that affect them (Bhatia, Rajiv, \& Corburn, 2011; Bourcier, Charbonneau, Cahill, \& Dannenberg, 2015).

Health Impact Project grantees are required to develop monitoring and evaluation plans, and evaluate the HIA process and early impacts within the grant period. Lessons learned from these HIAs are helping to inform how practitioners conduct HIAs, engage stakeholders, and disseminate products. Process evaluations are common, with practitioners determining whether the HIA was carried out according to the plan of action and applicable practice standards. A number of impact evaluations have examined the effect of HIAs on the decision-making process and the degree to which recommendations were adopted and implemented (Dannenberg, 2016). A recent study evaluated community participation in HIAs, including its impact on the success of an HIA (Center for Community Health and Evaluation and Human Impact Partners, 2015).

Outcome evaluations, which measure changes in health status or indicators resulting from implementation of the proposal, are rare because of methodological challenges such as confounding, effect modification, and meeting the epidemiologic standards for assessing causality. 
Appropriate methods and analytic techniques capable of assessing whether an HIA accurately predicted long-term health impacts need to be developed (Taylor, Gowman, \& Quigley, 2003). Despite these challenges, as the field continues to expand, we have seen how monitoring the implementation of HIA recommendations and evaluating the process, impact, or outcomes resulting from the HIA are being embraced as critical steps of the HIA process and not merely as an afterthought.

We are supporting additional well-designed evaluations to assess the impact of HIAs and the factors contributing to their success. For example, we are launching an independent, national evaluation that will examine the impact of HIAs on determinants of health and health equity and the conditions under which HIAs lead to impact on decisions. The findings from this work will be used to fill gaps in knowledge for HIA practitioners, policymakers, and funders and to inform our future investments.

Promoting Health Considerations in Federal Decisions In 2009, there were five completed HIAs on federal agency decisions, including three focused on the natural resources and energy sectors, one on agriculture and food policy, and one on labor and employment policy (Health Impact Project, n.d.-b). As of February 2016, there were 21 HIAs completed or in progress in the US on federal agency decisions, an increase of 320\% (Health Impact Project, n.d.-b). In 2010, the Affordable Care Act authorized the creation of the National Prevention Council to catalyze cross-sector collaboration across federal government agencies, in recognition that agencies responsible for our housing, education, transportation, and built environments can play a critical role in improving the public's health (U.S. Department of Health and Human Services, n.d.-a, n.d.-b). In 2011, the Council released the National Prevention Strategy, which prioritizes prevention, emphasizes evidence-based recommendations, and highlights HIA as an approach to use in reducing the burden of the leading causes of major illnesses and preventable death (National Prevention Council, 2011).

Although half of the HIAs completed or in progress to date on federal agency decisions have focused on natural resources or energy decisions, the topic areas in recent years include: policies on immigration; agriculture, food, and drug; housing; labor and employment; and transportation (Health Impact Project, n.d.-b). For example, HIAs have been used to inform: the U.S. Department of Agriculture's (USDA) nutrition standards for snack foods and beverages sold in schools; policies of the U.S. Equal Employment Opportunity Commission; federal immigration reform; federal paid sick leave policy; cleanup plans for a Superfund site; and numerous oil, gas, and mining permitting and project decisions (Health Impact Project, n.d.-b).

Federal agencies are also conducting or requesting HIAs. For example, regional offices of the U.S. Environmental Protection Agency (EPA) have used HIA to: (1) compare options for renovation and improvement at an elementary school in Massachusetts; (2) examine the impacts of a green infrastructure project on low-income, minority communities in Atlanta; and (3) examine expansion plans at the Ports of Los Angeles and Long Beach. The EPA has also integrated HIA into a federal environmental impact statement for a proposed expansion of the Red Dog Mine in Alaska (Health Impact Project, n.d.-b). In addition, the Health Impact Project collaborated with the U.S. Department of Housing and Urban Development (HUD) and partners from the Oregon Public Health Institute and Metropolitan Area Planning Council to conduct an HIA to inform an update of its designated housing rule and demonstrate how HIA might be used as a tool to advance the National Prevention Council's goals (Health Impact Project, 2015).

HIAs can bring a new lens of health to contentious policy debates, provide new data to inform federal policy, and develop collaborative relationships among agency staff, stakeholders, and advocates (Pollack, Heller, Givens, \& Lindberg 2013). HIAs have the potential to strengthen and supplement federal decision-making processes, such as through the use of HIA data in regulatory impact assessments and environmental impact assessments (as discussed previously). For example, the USDA highlighted the importance of the HIA on nutrition standards for snack foods and beverages sold in schools to their regulatory impact assessment, citing the HIA as "a recent, comprehensive, and groundbreaking assessment." The USDA also incorporated nearly all of the HIA recommendations in their interim-final rule (Health Impact Project, n.d.-a; U.S. Department of Agriculture, 2013). Furthermore, federal-level HIAs help policymakers engage with those affected by the policy decisions at a local level to fully understand the experience and possible effects of proposed policies (Health Impact Project, 2014).

Federal agencies face technical, economic, and political constraints in their decision-making and the HIA process needs to adapt and respond accordingly. In the designated housing rule HIA, for example, the goal was to provide HUD with data and information to inform the development of an updated rule. As a result, the assessment was conducted before the rule-making process began, necessitating the HIA team, in consultation with stakeholders, to develop and examine two scenarios of actions HUD could pursue in its rulemaking (Keppard et al., 2014). In the federal immigration reform HIA, the HIA team recognized the need for unique communication methods in the reporting phase, and used a national press call, legislative briefings, and videos, as well as developed a toolkit for advocates interested in communicating the findings and recommendations of the HIA to policymakers (Pollack, Heller, Givens, \& Lindberg 2013).

Federal decisions have far-reaching impact and the field has an important opportunity to impact public health by increasing the use of HIA and related approaches in federal decision-making. The relationships that we have established with federal agency staff will enable us to identify areas where a health lens can add value to federal decisions and yield benefits to health and health equity. We are adapting 
existing rapid HIA models for federal use. As part of the process, we will identify data sources, methods, and stakeholder input processes for integrating health considerations into federal policy in ways that the agencies can replicate and scale to fit the scope, resources, and timeline of a given decision. For example, in our recent work to inform HUD's update of its designated housing rule, we used existing structures that HUD could leverage in future decision-making, such as public housing resident advisory boards, to elicit stakeholder perspectives.

\section{Using HIA to Promote Health Equity}

Equity in health implies that everyone should have a fair opportunity to attain their full health potential and, more pragmatically, that none should be disadvantaged from achieving this potential if it can be avoided (World Health Organization, 1986). Health inequities are systematic differences in health status or the distribution of health resources between different subpopulations, resulting from social conditions. When groups face serious social, economic, and environmental disadvantages, health inequities are the result (American Public Health Association, 2015). HIAs address the root causes of health inequities by assessing the social determinants of health.

Equity is a core value that underpins HIA practice, initially described in the World Health Organization's Gothenburg Consensus Paper on HIA (Bhatia et al., 2014; World Health Organization European Centre for Health Policy, 1999). The HIA Practice Standards, first published in 2009 and most recently updated in 2014, require systematic consideration of the impacts of a proposed decision on health equity and development of recommendations to address equity impacts (Bhatia et al., 2014).

Although equity is a core value of HIA, the field would benefit from a more consistent and systematic approach to incorporating it into HIA practice. Many HIA practitioners and public health professionals need training and capacity building on how to address and incorporate equity in HIA. The Society of Practitioners of Health Impact Assessment (SOPHIA) published Equity metrics for health impact assessment practice as a reflective tool to evaluate the degree to which an HIA successfully incorporated equity and to help practitioners consider equity during the planning of their HIAs (SOPHIA Equity Working Group, n.d.).

One of the ways that HIA can promote equity is through its inclusive process and ability to build power within the community impacted by the decision. Community empowerment involves individuals acting collectively to gain greater influence and control over the determinants of health and the quality of life in their communities (Wallerstein, 2006; World Health Organization, 1998). HIAs can shift power to communities by bringing their voices to decisions, helping them take action, increasing community member contact with decision-makers, and helping strengthen the skills of community members to influence future decisions (Group
Health and Human Impact Partners, 2014).

Data collected by community groups, qualitative information from focus groups and interviews, as well as video and photo data projects, have all contributed meaningfully to our understanding of public health problems and solutions. Participatory research approaches can involve community members as full partners in research on decisions affecting them. Currently, most HIAs have some level of community involvement; however, few practitioners devote significant resources to community participation in the process (Center for Community Health and Evaluation and Human Impact Partners, 2015).

In the US, most HIAs are led by agencies or academic institutions; far fewer have been led by community-based organizations. There are several plausible reasons for the relatively low number of HIAs performed by communitybased organizations. One possibility is that mounting a successful proposal for HIA funding is beyond the capacity of smaller community organizations. Larger organizations and institutions typically have grant writers and other infrastructure, such as access to HIA training, which can facilitate their success in highly competitive grant programs. Most practitioners would agree that greater involvement by community-based organizations in HIA practice will lead to greater impact for HIAs, including the comprehensiveness of the assessment, the likelihood that the recommendations will be adopted and sustained, and the contributions to selfefficacy and social cohesion for participating organizations and participants.

We are examining our own funding mechanisms to ensure that community-based organizations and others focused on equity have the capacity and opportunity to conduct HIAs and related approaches. We are seeking to increase the use of HIA and related approaches in places and among populations that are experiencing widening health inequities, such as in southern and Appalachian states. In February 2016, the Health Impact Project announced grants to address factors outside of health care that influence population health and health equity in seven states: Alabama, Arkansas, Kentucky, Louisiana, Mississippi, Tennessee, and West Virginia (Health Impact Project, 2016). Grant recipients will use the first phase of funding to develop a community-driven plan of action, identifying the most pressing health equity issues and the upstream contributors to those issues. Following the planning phase, grantees will have the option of completing an HIA or using an alternative approach (e.g., health scoring criteria and other checklist-based tools, cross-sector initiatives to target social determinants of health). Grantees will also receive coaching and training on stakeholder engagement, HIA, Health in All Policies, and leadership skills. Finally, we are working with partners to provide training and technical assistance to increase the consideration of equity in HIA practice. We will continue to explore new approaches to promote health equity through our work, evaluate our efforts, and build on lessons learned to inform investments. 


\section{Conclusions}

HIAs and related approaches can effectively bring health information and perspectives from a broad set of stakeholders to decision-making. When we successfully and routinely factor health into the public policy process, we can create a future in which our social, economic, and built environ- ments enable all individuals in the US the opportunity to lead healthy lives. There are thousands of decisions made every day that affect health. Now is the time to consider health data and community voice in weighing tradeoffs, and use each decision as an opportunity to address the challenge of widening health inequities. 


\section{Health Impact Assessment: Informing Policy Around the Country}

\section{Growth of Health Impact Assessment}

As of 2009, 62 HIAs were completed or in progress. By January 2016, that figure was 386 .

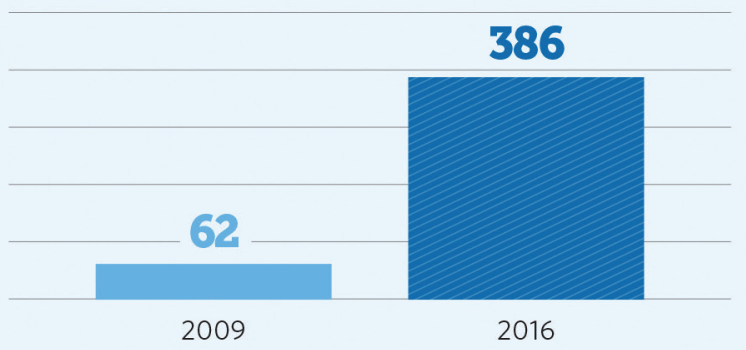

HIAs have been conducted in $\mathbf{4 1}$ states, the District of Columbia, and Puerto Rico and at the federal level.

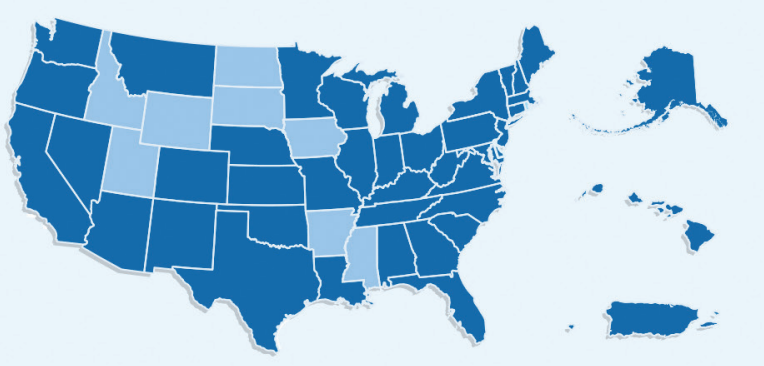

\section{Variety of Sectors}

About $70 \%$ focused on built environment, transportation, and natural resource decisions.

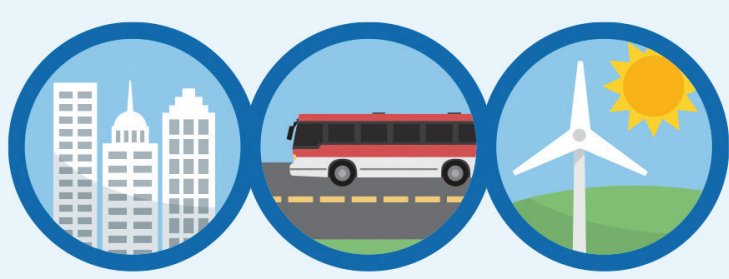

Roughly 30\% focused on the housing, agriculture, climate change, criminal justice, economic policy, and other sectors.

\section{Level of Decision Assessed}

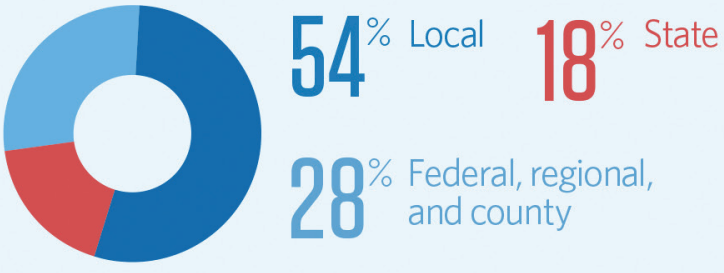

Over nearly seven years, the Health Impact Project-a collaboration of the Robert Wood Johnson Foundation and The Pew Charitable Trusts-has attracted and invested more than $\$ 22$ million in growing the field of practice. 


\section{References}

American Public Health Association. (2015). Better Health Through Equity: Case Studies in Reframing Public Health Work. Retrieved from: https://www.apha.org/ /media/files/pdf/topics/equity/equity stories.ashx

An Act Modernizing the Transportation Systems of the Commonwealth, Pub. L. No. Mass. Acts 2009 Chapter 25 (approved June 25, 2009) (2009). Retrieved from: https://malegislature.gov/Laws/SessionLaws/Acts/2009/

Bhatia, R., Farhang, L., Heller, J., Lee, M., Orenstein, M., Richardson, M., \& Wernham, A. (2014). Minimum Elements and Practice Standards for Health Impact Assessment, Version 3. Retrieved from: http://hiasociety.org/wp-content/ uploads/2013/11/HIA-Practice-Standards-September-2014.pdf

Bhatia, R., Rajiv, \& Corburn, J. (2011). Lessons from San Francisco: Health Impact Assessments Have Advanced Political Conditions for Improving Population Health. Health Affairs, 30(12), 2410-8. http://dx.doi.org/10.1377/hlthaff.2010.1303

Bourcier, E., Charbonneau, D., Cahill, C., \& Dannenberg, A. (2014). Do health impact assessments make a difference? A national evaluation of HIAs in the United States. Retrieved from: http://www.rwjf.org/content/dam/farm/reports/issue briefs/2014/rwjf409204/subassets/rwjf409204_1

Bourcier, E., Charbonneau, D., Cahill, C., \& Dannenberg, A. (2015). An Evaluation of Health Impact Assessments in the United States, 2011-2014. Preventing Chronic Disease, 12(E23), 1-10. http://dx.doi.org/10.5888/pcd12.140376

Center for Community Health and Evaluation and Human Impact Partners. (2015). Community Participation in Health Impact Assessments: A National Evaluation. Seattle. Retrieved from: http://www.humanimpact.org/wp-content/uploads/ Full-report Community-Participation-in-HIA-Evaluation.pdf

Charter Township of Meridian. (n.d.). Charter Township of Meridian Health Impact Assessment. Retrieved March 7, 2016, from: http://advance.captus.com/planning/hia2/pdf/Module2/Ingham County Meridan Township Checklist.pdf

Dannenberg, A. L. (2016). Effectiveness of Health Impact Assessment: A Synthesis of Data from Five Impact Evaluation Reports. Prev Chronic Dis 13:150559. http://dx.doi.org/10.5888/pcd13.150559

Enterprise Green Communities. (2015). 2015 Enterprise Green Communities Criteria. Retrieved from: http://www. enterprisecommunity.com/solutions-and-innovation/enterprise-green-communities/criteria

Group Health and Human Impact Partners. (2014). Community Participation in Health Impact Assessments: National Survey Results. Retrieved from: http://www.humanimpact.org/capacity-building/hia-tools-and-resources/

Health Impact Project. (n.d.-a). Health Impact Assessment: National Nutrition Standards for Snack and a la Carte Foods. Retrieved April 21, 2015, from: http://www.pewtrusts.org/hip/national-nutrition-standards-for-snack-and-a-la-carte-foodsand-beverages.html

Health Impact Project. (n.d.-b). HIA in the United States. Retrieved January 8, 2016, from: http://www.pewtrusts.org/en/ multimedia/data-visualizations/2014/hia-in-the-united-states

Health Impact Project. (2014). Health Impact Assessment of Proposed Changes to the Supplemental Nutrition Assistance Program. Washington, DC. Retrieved from: http://www.pewtrusts.org/en/research-and-analysis/white-papers/2014/11/ health-impact-assessment-of-proposed-changes-to-the-supplemental-nutrition-assistance-program

Health Impact Project. (2015). Connecting Public Housing and Health: A Health Impact Assessment of HUD's Designated Housing Rule. Retrieved February 23, 2016, from: http://www.pewtrusts.org/en/research-and-analysis/issuebriefs/2015/06/connecting-public-housing-and-health

Health Impact Project. (2016). Health Impact Project Provides Funding to Promote Health in Southern and Appalachian States. Retrieved March 7, 2016, from: http://www.pewtrusts.org/en/about/news-room/press-releases/2016/02/24/ health-impact-project-provides-funding-to-promote-health-in-southern-and-appalachian-states

Health Impact Project and Arizona State University. (2012). Legal Review Concerning the Use of Health Impact Assessments in Non-Health Sectors. Retrieved from: http://www.pewtrusts.org/en/research-and-analysis/reports/2012/04/04/legalreview-concerning-the-use-of-health-impact-assessments-in-nonhealth-sectors

Institute of Medicine. (2014). Financing Population Health Improvement - Workshop Summary. Washington, DC. Retrieved from: http://www.iom.edu/Reports/2014/Financing-Population-Health-Improvement.aspx

Keppard, B., James, P., Ito, K., Sportiche, N., Martin, C., Givens, M.,...Arcaya, M. (2014). Assessing the Health Impacts of Public Housing for Low Income Elderly and Disabled Residents - An HIA for a Proposed Federal Designated Housing Rule. In American Public Health Association Annual Meeting. Retrieved from: https://apha.confex.com/apha/142am/ webprogram/Session40696.html

Massachusetts Department of Transportation. (n.d.). Healthy Transportation Compact. Retrieved April 26, 2014, from: http://www.massdot.state.ma.us/GreenDOT/HealthyTransportation/HealthyTransportationCompact.aspx 
Nashville Area Metropolitan Planning Organization. (n.d.). Health and Well Being. Retrieved March 5, 2016, from: http:// www.nashvillempo.org/regional plan/health/

National Conference of State Legislatures. (2014). An Analysis of State Health Impact Assessment Legislation. Retrieved from: http://www.ncsl.org/research/environment-and-natural-resources/an-analysis-of-state-health-impact-assessmentlegislation635411896.aspx

National Prevention Council. (2011). National Prevention Strategy. Washington, DC. Retrieved from: http://www. surgeongeneral.gov/initiatives/prevention/strategy/report.pdf

National Research Council. (2011). Why We Need Health-Informed Policies and Decision-Making. In Improving Health in the United States: The Role of Health Impact Assessment (pp. 23-42). Washington, DC: National Academies Press. Retrieved from: http://www.nap.edu/catalog.php?record id=13229

Pollack, K., Heller, J., Givens, M., \& L. R. (2013). Federal Health Impact Assessment: Lessons Learned. In Conference Session at the National Health Impact Assessment Meeting.

SOPHIA Equity Working Group. (n.d.). Equity Metrics for Health Impact Assessment Practice, Version 1. Retrieved from: http://www.hiasociety.org/documents/EquityMetrics FINAL.pdf

Taylor L., Gowman N., \& Quigley, R. (2003). Evaluating health impact asessment. Retrieved from: http://www.who.int/hia/ evidence/en/practice.pdf

U.S. Department of Agriculture. National School Lunch Program and School Breakfast Program: Nutrition Standards for All Foods Sold in School as Required by the Healthy, Hunger-Free Kids Act of 2010; Interim Final Rule, 78 Federal RegisterDepartment of Agriculture 1-54 (2013). Retrieved from: http://www.fns.usda.gov/sites/default/files/2013-15249 0.pdf

U.S. Department of Health and Human Services. (n.d.-a). About the Law. Retrieved April 21, 2015, from: http://www.hhs. gov/healthcare/rights/law/index.html

U.S. Department of Health and Human Services. (n.d.-b). National Prevention Council. Retrieved April 21, 2015, from: http://www.surgeongeneral.gov/initiatives/prevention/about/index.html

Wallerstein, N. (2006). What is the evidence on effectiveness of empowerment to improve health? Coppenhagen. Retrieved from: http://www.euro.who.int/Document/E88086.pdf

World Health Organization. (1986). Social justice and equity in health: Report on a WHO meeting (ICP/HSR 804/m02). Copenhagen.

World Health Organization. (1998). Health Promotion Glossary. Geneva. Retrieved from: http://www.who.int/ healthpromotion/about/HPG/en/

World Health Organization European Centre for Health Policy. (1999). Health Impact Assessment: Main concepts and suggested approach (Gothenburg Consensus Paper). Brussels.

\section{CORRESPONDING AUTHOR}

Rebecca Morley

Health Impact Project

The Pew Charitable Trusts

901 E Street NW, 10th Floor

Washington, DC 20004

rmorley@pewtrusts.org

\section{ACKNOWLEDGEMENTS}

Work on this article was supported by a grant to the Health Impact Project from the Robert Wood Johnson Foundation. The authors thank Amber Lenhart for her assistance with references.

\section{CHIA STAFF}

Editor-in-Chief

Cynthia Stone, Richard M. Fairbanks School of Public Health Indiana University-Purdue University Indianapolis

Journal Manager

Lyndy Kouns, Richard M. Fairbanks School of Public Health Indiana University-Purdue University Indianapolis

Chronicles of Health Impact Assessment Vol. 1, No. 1 (2016) DOI: 10.18060/21352

(C) 2016 Author(s): Morley, R; Lindberg, R; Rogerson, B; Bever, E.; Pollack, K.M.

(cc)BY

This work is licensed under a Creative Commons Attribution 4.0 International License. 